\title{
FORMULAÇÃO DE DECISÕES ADMINISTRATIVAS EM MATÉRLA DE DIREITOS HUMANOS
}

\author{
THE FORMULATION OF ADMINISTRATIVE DECISIONS ON \\ HUMAN RIGHTS \\ Eduardo Biacchi Gomes ${ }^{1}$ \\ Pedro Henrique Brunken Flores ${ }^{1}$
}

\begin{abstract}
Recebido em: 19/03/2018 Aceito em: 08/07/2019

eduardobiacchigomes@gmail.com phbflores@gmail.com
\end{abstract}

Resumo: Na contemporaneidade os direitos humanos possuem um papel fundamental no mundo. Através da sua concepção contemporânea, mais especificamente após a metade do século $X X$, eles - direitos humanos - ganharam força com o seu discurso de proteção aos direitos do homem, elencando o princípio da dignidade da pessoa humana como pedra angular de todos os sistemas jurídicos efetivamente preocupados com o bem-estar dos cidadãos. Nesse sentido, então, os Estados de Direito encontram-se vinculados à atividade de proteção e realização de tais direitos, devendo buscar sempre os melhores meios para atingir estes fins. É nesse sentido que o presente trabalho possui seu mote. Busca-se demonstrar, através, da análise do instituto do controle de convencionalidade pelos Tribunais a sua aplicabilidade e utilização também pela Administração Pública brasileira na formulação de políticas públicas, de tal sorte que as decisões administrativas levem em conta, para além das leis escritas e das normas e princípios constitucionais trazidos pela Constituição de 1988, os dispositivos constantes nos tratados e convenções internacionais de direitos humanos, garantindo, assim, decisões justas e de acordo com os anseios da modernidade. Para atingir tal fim, portanto, a pesquisa foi realizada através de levantamento bibliográfico sobre o tema, valendo-se do método dedutivo.

Palavras-chave: Administração Pública. Controle de Convencionalidade. Direitos Humanos. Poder Judiciário. Políticas Públicas.

\begin{abstract}
In contemporaneity the human rights have a founding role in the world. Through your contemporany conception, more specifically after de second half of de XX century, they - the human rights - won strenght with his speech of men rights protection, guiding the human dignity principle as a angular stone for all legal system's effectively concerned with de well-being citizens. In this sense, the Rule of Law is linked to the activity of protection and achievement of those rights and should seek Always the best ways to achieve those ends. It's in this sense that the presente paper has its intentions. It seeks to demonstrate, through the analysis of the institute of control of conventionality by the Courts, its applicability and its use also by the Brazilian Public Administration in the formulation of public policies, in such a way that administrative decisions take into account, in addition to written and of the constitutional norms and principles brought by the 1988 Constitution, the provisions contained in international treaties and conventions on human rights, thus guaranteeing fair decisions and in accordance with the yearnings of modernity. To reach this end, therefore, the research was carried out through a bibliographical survey on the subject, using the deductive method.
\end{abstract}

Keywords: Public Administration. Control of Conventionality. Human Rights. Judicial Power. Public Policy.

\footnotetext{
${ }^{1}$ Centro Universitário Autônomo do Brasil - UniBrasil - Curitiba - Paraná - Brasil
} 


\section{INTRODUÇÃO}

O surgimento e construção dos direitos humanos, da específica preocupação com os direitos dos homens e dos cidadãos, com a manutenção de sua dignidade foi colocado em pauta, sendo considerado fator importante para todas as discussões que envolvem o Direito.

Aos estudiosos das ciências jurídicas restou um importante papel pelos caminhos da história no sentido de sempre buscar meios de garantir que tais direitos inerentes aos cidadãos sejam respeitados e concretizados, buscando garantir que os homens não sejam mais subjugados e que suas vidas sejam vistas e tratadas apenas como meros detalhes em sociedades notadamente absolutas.

Assim, impende ao Direito e, notadamente para atingir os fins do presente trabalho, ao Direito Administrativo, a partir desta nova concepção valorativa da dignidade do homem, um papel de protetor e garantidor de que o indivíduo possa sempre ter o seu lugar ao sol, com segurança e vida digna.

Desse modo, os juristas devem ter como papel primário buscar a construção de mecanismos e instrumentos, pela via da dogmática do Direito, que sejam aptos a dar azo às necessidades das sociedades e de seus indivíduos, garantindo um cenário de dignidade e proteção dos seus direitos mais básicos.

Essa é a intenção do presente texto. Procurar-se-á, a partir de uma construção bibliográfica, trazer à baila uma proposta de instrumento a ser utilizado, notadamente no cenário do Brasil pós Constituição Federal de 1988, que tenha por condão garantir a ideal e real consecução dos direitos humanos e fundamentais dos homens.

A proposta, especificamente, tem por intuito lançar mão da ideia de uma ação da Administração Pública que, ao decidir questões a si inerentes, tome como ponto fundante o respeito aos direitos humanos e o insculpido nos tratados e convenções internacionais. Isto é, formule decisões administrativas pautadas na dignidade da pessoa humana e com o intuito de realizar e proteger os direitos humanos e fundamentais dos homens.

Para isso, o texto abordará, em um primeiro momento, o tema da construção dos direitos humanos no mundo moderno, bem como qual o modelo de Administração Pública que deve ser levado em consideração para atingir o seu fim e a força imprimida pela Constituição Federal de 1988 nessa matéria, qual seja, consecução e proteção dos direitos humanos.

A partir de tal construção, pretende-se demonstrar com o decorrer do texto que a Administração Pública brasileira frequentemente tem em seu âmbito decisório que lidar com questões diretamente ligadas a proteção e manutenção dos direitos dos homens, notadamente no que tange à manutenção da dignidade pertencente a cada um deles.

Aqui, então, tem-se como intenção demonstrar que ao decidir questões envolvendo essa disciplina, o Estado Administração deve ter zeloso cuidado ao formular suas decisões, uma vez que elas devem ter o condão de vincular a matéria, a fim de garantir uma maior racionalidade de suas decisões e, consequentemente, uma maior concretização de direitos. Para chegar a tal fim, contudo, 
passa-se antes pela questão do controle de convencionalidade exercido pelos Tribunais, de modo a entender tal instituto.

O grande mote do presente artigo é procurar evidenciar que o denominado controle de convencionalidade, comumente aplicado dentro do judiciário vincula, em um plano maior o Estado e os seus poderes (Executivo, Legislativo e o Judiciário), vez que tem por objetivo garantir a aplicação dos tratados ratificados pelo Estado no plano interno, sob pena de ensejar a responsabilidade internacional do Estado como um todo. ${ }^{2}$

Desse modo, pretende-se demonstrar que a vinculação da Administração Pública às suas próprias decisões em matéria de direitos humanos é um instrumento apto à garantia de sua ideal proteção, a partir de uma necessidade imanente de observação dos preceitos insculpidos nas convenções e tratados internacionais e da própria possibilidade de um controle de convencionalidade a ser elaborado por si. Sendo essa a intenção, a presente construção se valerá da pesquisa bibliográfica, a partir da utilização do método dedutivo, de sorte a permitir o ideal desenvolvimento das ideias e hipóteses aqui levantadas.

\section{DIREITOS HUMANOS NA ORDEM CONSTITUCIONAL E ADMINISTRAÇÃO PÚBLICA BRASILEIRA}

A noção moderna de direitos humanos se dá a partir de sua própria construção histórica, pela qual a doutrina do direito constitucional e internacional ${ }^{3} \mathrm{com}_{\text {grande }}$ competência já se debruçou. Importa, no entanto, retomar algumas concepções a respeito dessas construções, a fim de se permitir uma melhor compreensão do presente texto. Fazse necessário, assim, por razões inclusive metodológicas, que se trace, brevemente, alguns apontamentos importantes a respeito da construção dos direitos humanos notadamente a partir da segunda metade do século XX, momento em que a reafirmação dos direitos dos homens se tornou, diante dos efeitos nefastos causados pelas grandes guerras, necessária

Não se nega, todavia, que antes deste momento em específico na história do mundo, outros movimentos ${ }^{4}$ tenham dado força ao discurso das liberdades individuais e da igualdade entre os

2 FERRAÇO, André Augusto Giuriatto; MORAES, Gabriela Garcia Batista Lima. O controle de convencionalidade do crime de desacato e o sistema interamericano de direitos humanos na redemocratização na américa-latina: uma análise com base no caso brasileiro. Revista do Direito, Santa Cruz do Sul, v. 2, n. 55, p. 76-95, maio 2018. ISSN 1982-9957. Disponível em: <https://online.unisc.br/seer/index.php/direito/article/view/11875/7665>. Acesso em: 21 jun. 2019. doi:https://doi.org/10.17058/rdunisc.v2i55.11875.

3 Para aprofundamento a respeito da construção histórica dos direitos humanos, especialmente no pós-guerra, ver, dentre outros: COMPARATO, Fábio Konder. A afirmação histórica dos direitos humanos. 4. ed. rev. e atual. São Paulo: Saraiva, 2005; BOBBIO, Norberto. A era dos direitos. Rio de Janeiro: Elsevier. 2004.

${ }^{4}$ Celso Lafer afirma, nesse sentido, que "no plano interno, a primeira afirmação histórica consequente da noção de direitos humanos, como se sabe, dá-se no século XVIII, com as Revoluções Americana e Francesa. Trata-se de uma verdadeira inovação com relação aos modos tradicionais de pensar a política. (...). As duas revoluções inauguram a época da perspectiva dos governados, a da plena legitimação da visão ex parte Populi. Assiste-se, como registra Bobbio, à substituição da ênfase na noção de dever dos súditos pela promoção da noção de direitos dos cidadãos. Daí, nas palavras de 
homens, a exemplo da Revolução Francesa de 1789, que nas palavras de Norberto Bobbio marcou "o fim último de uma época e o princípio primeiro de uma outra"5.

Parece certo, no entanto, que falar em direitos humanos contemporâneos, a partir de uma concepção de um Estado de Direito preocupado com a proteção do homem e de sua dignidade, tem seu lugar após a metade do século XX.

É nesse sentido, então, que se pode dizer que, após o fim da segunda guerra mundial, os direitos humanos ganham uma concepção contemporânea, fruto de um movimento de internacionalização, cuja intenção era a de responder "às atrocidades e horrores cometidos durante o nazismo"6.

Concepção contemporânea essa que tem como ponto de apoio o advento da Declaração Universal de Direitos Humanos de 1948, que insculpiu já em seu preâmbulo que "o reconhecimento da dignidade inerente a todos os membros da família humana e de seus direitos iguais e inalienáveis é o fundamento da liberdade, da justiça e da paz no mundo"7.

De fato, a aprovação da Declaração Universal dos Direitos Humanos passou a ser considerada "como marco maior do processo de reconstrução dos direitos humanos", trazendo em seu texto pontos inovadores cujas consequências atingiram diretamente as formas de se ver as relações entre Estados, bem como de se entender e interpretar a própria noção de soberania estatal e, ainda mais, "na cristalização da ideia de que o indivíduo deve ter direitos protegidos na esfera internacional, na condição de sujeito de Direito"8.

Nessa linha de pensar, aponta Fábio Konder Comparato que

A declaração Universal, aprovada pela Assembleia Geral das Nações Unidas em 10 de dezembro de 1948, e a Convenção Internacional sobre a prevenção e punição do crime de genocídio, aprovada um dia antes também no quadro da ONU, constituem os marcos inaugurais da nova fase histórica, que se encontra em pleno desenvolvimento9 ${ }^{9}$

Ou seja, a partir deste momento, se torna perceptível uma virada na forma de se pensar os direitos dos homens, colocando-se como ponto mais importante o respeito e proteção à dignidade da

Hannah Arendt, a ideia do 'direito de ter direitos', que estará na base da construção dos regimes democráticos da Idade Contemporânea. O poder do governante - ou a soberania ilimitada, no plano interno - passa a ter limites. A raison d'état é contida. Abre-se uma nova possibilidade de favorecer a convergência entre a Ética e a Política, num regime que tem como regra básica, na fórmula de Bobbio, a ideia de que é melhor 'contar cabeças do que cortar cabeças'. LAFER, Celso. A ONU e os direitos humanos. Estudos avançados. v. 9, n. 25, São Paulo, set/dec. 1995. Disponível em: <http://www.scielo.br/scielo.php?pid=S0103-40141995000300014\&script=sci_arttext\&tlng=pt>.

Acesso em: 27 ago. 2017. p. 170-71.

${ }^{5}$ BOBBIO, Norberto. A era dos direitos. Rio de Janeiro: Elsevier. 2004. p. 103.

6 PIOVESAN, Flávia. A universalidade e a indivisibilidade dos direitos humanos: desafios e perspectivas. In: BALDI, César Augusto (Org.). Direitos humanos na sociedade cosmopolita. Rio de Janeiro: Renovar. 2004. p. 46.

7 ORGANIZAÇÃO DAS NAÇÕES UNIDAS (ONU). Declaração universal dos direitos humanos. 1948.

8 PIOVESAN, Flávia. A universalidade e a indivisibilidade dos direitos humanos: desafios e perspectivas. In: BALDI, César Augusto (Org.). Direitos humanos na sociedade cosmopolita. Rio de Janeiro: Renovar. 2004. p. 48.

9 COMPARATO, Fábio Konder. A afirmação histórica dos direitos humanos. 4. ed. rev. e atual. São Paulo: Saraiva, 2005. p. 56. 
pessoa humana. Esta nova perspectiva, então, cria um novo movimento de "expansão das organizações de cooperação internacional, e, consequentemente, a solidificação dos direitos humanos no cenário internacional"10.

Há, assim, uma perspectiva que fortalece os direitos humanos para além do plano interno dos Estados, se tem, a partir deste momento, uma preocupação em se fortalecer tal domínio também no plano internacional, isto é: Os Direitos do Homem transpassam as fronteiras domésticas e passam a ser tema de interesse universal11.

Pode-se afirmar, desse modo, que a partir do desenvolvimento da Declaração Universal dos Direitos Humanos de 1948 se tem início o desenvolvimento, como bem aponta Flávia Piovesan, de um Direito Internacional dos Direitos Humanos em que se tem "a adoção de inúmeros tratados internacionais voltados à proteção dos direitos fundamentais", de modo a dar azo a instrumentos de proteção destes direitos que "refletem, sobretudo, a consciência ética contemporânea compartilhada pelos estados, na medida em que invocam o consenso internacional acerca de temas centrais aos direitos humanos"12.

No mesmo sentido, aponta Flávia Piovesan que o Sistema Interamericano de Proteção aos Direitos Humanos, dentro do contexto atual é um instrumento efetivo e garantidor na tutela dos referidos direitos, inclusive nos direitos relativos à saúde. ${ }^{13}$

Assim, pode-se dizer que a Declaração de 1948 foi marco fundamental para esta nova perspectiva dos direitos humanos, sendo que, após o seu advento, o mundo se deparou com inúmeros outros textos, declarações e convenções que trazem em seu bojo preocupações imanentes à disciplina dos direitos humanos.

São exemplos importantes de textos trazidos à baila ${ }^{14}$ : Os Pactos Internacionais de Direitos Humanos de 1966¹5; a Convenção Europeia de Direitos Humanos de 1950; a Convenção Americana

10 FACHIN, Melina Giraldi. Fundamentos dos direitos humanos: teoria e práxis na cultura da tolerância. Rio de Janeiro: Renovar. 2009. p. 161.

11 PIOVESAN, Flávia. A Constituição brasileira de 1988 e os tratados internacionais de proteção aos direitos humanos. Revista Jurídica da Faculdade de Direito Dom Bosco (EOS). v. 2, n. 1, ano II, 2014. Disponível em: <http://www.dombosco.sebsa.com.br/faculdade/revista_direito/3edicao.php>. Acesso em: 24 ago. 2017. p. 21.

12 PIOVESAN, Flávia. A Constituição brasileira de 1988 e os tratados internacionais de proteção aos direitos humanos. Revista Jurídica da Faculdade de Direito Dom Bosco (EOS). v. 2, n. 1, ano II, 2014. Disponível em: <http://www.dombosco.sebsa.com.br/faculdade/revista_direito/3edicao.php>. Acesso em: 24 ago. 2017. p. 23.

${ }^{13}$ PIOVESAN, Flavia; DE FREITAS, Daniel Castanha. O pacto de San José da Costa Rica e a jurisprudência interamericana em matéria de direito à saúde. Revista do Direito, Santa Cruz do Sul, v. 1, n. 54, p. 205-225, jan. 2018. ISSN 1982-9957. Disponível em:

$<$ https://online.unisc.br/seer/index.php/direito/article/view/11843/7331>. Acesso em: 21 jun. 2019. doi:https://doi.org/10.17058/rdunisc.v1i54.11843.

${ }^{14}$ Não se tem por intenção citar todos os importantes textos que vieram à baila após o advento da Declaração Universal de 1948, mas tão somente, de forma concisa, mostrar alguns cuja importância se mostra ímpar para o presente texto, notadamente no que se refere ao Pacto de São José da Costa Rica e a Convenção de Viena de 1993. Para aprofundar o estudo sobre os textos referentes à proteção dos direitos humanos, ver: COMPARATO, Fábio Konder. A afirmação histórica dos direitos humanos. 4. ed. rev. e atual. São Paulo: Saraiva, 2005.

${ }^{15}$ Segundo Fábio Konder Comparato, tais pactos foram responsáveis por desenvolver pormenorizadamente o conteúdo da Declaração Universal de 1948 (COMPARATO, Fábio Konder. A 
de Direitos Humanos, também conhecida como Pacto de São José da Costa Rica ${ }^{16}$; a Carta Africana dos Direitos Humanos ${ }^{17}$; bem como os resultados inerentes à Segunda Conferência Mundial sobre Direitos Humanos realizada em Viena, em 1993, na qual se fez uma nova avaliação global dos instrumentos internacionais de implementação e proteção de direitos humanos, abrindo-se campo para o estudo das perspectivas esperadas no futuro e para o estudo do aperfeiçoamento dos mecanismos de proteção em matéria de direitos humanos ${ }^{18}$.

O escrito até aqui tem por razão permitir uma compreensão a respeito da construção histórica e fundamental dos direitos humanos a partir de sua concepção contemporânea, ou seja, a partir da metade do século XX, especialmente após o fim da segunda grande guerra mundial.

Pretendeu-se, neste ínterim, deixar claro que a ideia contemporânea de direitos humanos vem notadamente com o intuito de dar uma resposta às atrocidades cometidas contra os homens naquele período de tempo. Mais do que isso, resta importante deixar claro que há o nascimento de uma preocupação efetiva com a proteção dos direitos mais básicos dos homens e de sua dignidade, construindo-se, assim, com o passar dos tempos um arcabouço jurídico-internacional para esse fim.

Este arcabouço jurídico internacionaliza as relações entre os Estados, relativizando a própria ideia de soberania interna em prol dos ideais trazidos pela Declaração Universal de 1948 e dos seus documentos subsequentes.

A partir desta ideia e da real percepção de que os Estados de Direito devem se preocupar com o bem-estar dos seus cidadãos para além da mera garantia de sua liberdade e igualdade em sentido formal (princípio liberal), inicia-se um movimento de incorporação, por parte dos Estados membros das Nações Unidas, dos Tratados e Convenções de Direitos Humanos, especificamente com o intuito de impedir que atos atrozes voltem a ocorrer e de garantir a devida proteção e dignidade da pessoa humana.

Assim, a partir deste momento, pode-se falar em um Sistema Internacional de Direitos Humanos, do qual, no entanto, o Brasil apenas tomou posição a partir do seu processo de redemocratização em 1985, como bem aponta Flávia Piovensan:

No que se refere à posição do Brasil em relação ao sistema internacional de proteção dos direitos humanos, observa-se que somente a partir do

afirmação histórica dos direitos humanos. 4. ed. rev. e atual. São Paulo: Saraiva, 2005. p. 275 e ss.).

${ }^{16}$ Segundo Fábio Konder Comparato: "Aprovada na Conferência de São José da Costa Rica em 22 de novembro de 1969, a Convenção reproduz a maior parte das declarações de direitos constantes do Pacto Internacional de Direitos civis e políticos de 1966. Quanto aos órgãos competentes para supervisionar o cumprimento de suas disposições e julgar os litígios referentes aos direitos humanos nela declarados, a Convenção aproxima-se mais do modelo da Convenção Européia de Direitos Humanos de 1950" (COMPARATO, Fábio Konder. A afirmação histórica dos direitos humanos. 4. ed. rev. e atual. São Paulo: Saraiva, 2005. p. 362 e ss.).

${ }_{17}$ A grande novidade desta Carta se traduziu na afirmação de "os povos são também titulares de direitos humanos, tanto no plano interno como na esfera internacional" (COMPARATO, Fábio Konder. A afirmação histórica dos direitos humanos. 4. ed. rev. e atual. São Paulo: Saraiva, 2005. p. 391 e Ss.).

${ }^{18}$ CANÇADO TRINDADE, Antônio Augusto. Dilemas e desafios da proteção internacional dos direitos humanos no limiar do século XXI. Revista brasileira de Política Internacional. Vol. 40, n. 1, Brasília, jan/jun. $1997 . \quad$ Disponível em: <http://www.scielo.br/scielo.php?pid=S003473291997000100007\&script=sci_arttext\&tlng=pt>. Acesso em: 30 ago. 2017. p. 167-68. 
processo de redemocratização do país, deflagrado em 1985, é que o estado brasileiro passou a ratificar relevantes tratados internacionais de direitos humanos. O marco inicial do processo de incorporação de tratados internacionais de direitos humanos pelo Direito brasileiro foi a ratificação, em 1989, da Convenção contra a Tortura o Outros Tratamentos Cruéis, Desumanos ou Degradantes. A partir dessa ratificação, inúmeros outros importantes instrumentos internacionais de proteção dos direitos humanos foram também incorporados pelo Direito Brasileiro, sob a égide da Constituição Federal de $1988^{19}$

Com a promulgação da Constituição Federal de 1988, então, se tem um novo momento político e democrático no país, passando de um modelo de Estado antes tido como autoritário para um Estado Democrático e de Direito efetivamente preocupado com os direitos fundamentais e direitos humanos ${ }^{20}$.

Sob essa ótica, então, o texto constitucional traz dispositivos que demonstram uma efetiva preocupação com a proteção dos direitos humanos, através, especialmente, dos parágrafos $2^{0}$ e $3^{\circ}$ do seu artigo $5^{\circ}$ que, como bem expõem Eduardo Biacchi Gomes e Ane Elise Brandalise Gonçalves, "dão ensejo ao uso dos tratados internacionais de direitos humanos no direito doméstico, de forma que se vive em um momento diferente daquele vivido à época dos regimes autoritários"21.

Consequência natural e lógica da existência do artigo $5^{\circ}$ da Constituição da República Federativa do Brasil, especialmente no que diz respeito aos direitos fundamentais, reside no fato de que o constituinte originário impôs para a própria Administração Pública limites na sua atuação e que, naturalmente, não podem violar os direitos fundamentais e os próprios tratados de direitos humanos ratificados pela República Federativa do Brasil. ${ }^{22}$

A partir destes dispositivos, assim, e sob a lógica de que o princípio da dignidade humana e os direitos fundamentais são princípios constitucionais centrais do sistema constitucional como um todo, se faz possível a interpretação de que o Direito Brasileiro e os tratados internacionais estão em um constante processo de interação. O próprio parágrafo $2^{\circ}$ do artigo $5^{\circ}$ da Constituição Federal aduz que "Os direitos e garantias expressos nesta Constituição não excluem outros decorrentes do regime

19 PIOVESAN, Flávia. A Constituição brasileira de 1988 e os tratados internacionais de proteção aos direitos humanos. Revista Jurídica da Faculdade de Direito Dom Bosco (EOS). v. 2, n. 1, ano II, 2014. Disponível em: <http://www.dombosco.sebsa.com.br/faculdade/revista_direito/3edicao.php>. Acesso em: 24 ago. 2017.

20 Para aprofundamento no estudo a respeito da promulgação da Constituição Federal de 1988, ver: BARROSO, Luís Roberto. Curso de direito constitucional contemporâneo: os conceitos fundamentais e a construção do novo modelo. 5. ed. São Paulo. Saraiva. 2014. VitalBook file. Disponível em: <http://integrada.minhabiblioteca.com.br/books/9788502228061>. Acesso em: 27 set. 2016. p. 492.

${ }^{21}$ GOMES, Eduardo Biacchi; GONÇALVES, Ane Elise Brandalise. O controle de convencionalidade, a convenção americana de direitos humanos e o crime de desacato. Revista Jurídica da Presidência. v. 18, n. 114, fev/maio, Brasília. 2016. p. 73-96. Disponível em: <https://revistajuridica.presidencia.gov.br/index.php/saj/article/view/1207>. Acesso em: 27 ago. 2017. 22 BRUGGER, Winfried; LEAL, Monia. Os direitos fundamentais nas modernas constituições: análise comparativa entre as Constituições Alemã, Norte-americana e Brasileira. Revista do Direito, Santa Cruz do Sul, p. 123-142, jul. 2007. ISSN 1982-9957. Disponível em: $<$ https://online.unisc.br/seer/index.php/direito/article/view/184/143>. Acesso em: 21 jun. 2019. doi:https://doi.org/10.17058/rdunisc.v0i28.184. 
e dos princípios por ela adotados, ou dos tratados internacionais em que a República Federativa do Brasil seja parte"23. Ou seja, resta clara a importância dada aos tratados internacionais em matéria de direitos humanos, de modo a garantir os próprios ideais de um modelo de Estado Democrático e de Direito.

Nesta esteira, merece destaque a adesão do Brasil ao Pacto de São José da Costa Rica, conforme leciona Fernando Luiz Ximenes Rocha:

[...] merece relevo a adesão do Brasil, ainda que serôdia, à Convenção Americana sobre Direitos Humanos, também conhecida por Pacto de San José da Costa Rica, formalizada pelo Decreto ํo. 678, de 6 de novembro de 1992, e a posição feliz do nosso constituinte de 1988, ao consagrar que os direitos garantidos nos tratados de direitos humanos em que a República Federativa do Brasil é parte e recebe tratamento especial, inserindo-se no elenco dos direitos constitucionais fundamentais, tendo aplicação imediata no âmbito interno, a teor do disposto nos parágrafos $1^{\circ}$ e $2^{\circ}$ do art. $5^{\circ}$ da Constituição Federal ${ }^{24}$.

Há, de fato, uma grande inovação albergada pelo texto constitucional que para além dos direitos fundamentais inscritos especialmente nos artigos $5^{\circ}$ e $6^{\circ}$, abre o seu leque também para os direitos constantes dos tratados internacionais subscritos pelo Brasil, atribuindo-os, assim, um grau de hierarquia especial equivalente ao de norma constitucional ${ }^{25}$.

Afinal, essa parece ser a pretensão da Constituição Federal de 1988: garantir, fomentar e proteger os direitos mais básicos dos homens, a fim de promover as verdadeiras intenções de um Estado Democrático e de Direito, cujo um de seus fundamentos basilares é o princípio da dignidade da pessoa humana ${ }^{26}$.

Todavia, para além da simples menção no texto, deve o Estado - a partir da ação dos três poderes da República - encontrar meios de garantir a plena e ideal consecução dos dispositivos ali elencados, com o intuito primeiro de garantir a proteção e consecução dos direitos humanos e fundamentais.

Nessa linha de raciocínio parece certo, ademais, que a competência primeira nessa garantia, em especial de dar cumprimento material aos dispositivos jusfundamentais, pertence à

${ }^{23}$ PIOVESAN, Flávia. A Constituição brasileira de 1988 e os tratados internacionais de proteção aos direitos humanos. Revista Jurídica da Faculdade de Direito Dom Bosco (EOS). v. 2, n. 1, ano II, 2014. Disponível em: <http://www.dombosco.sebsa.com.br/faculdade/revista_direito/3edicao.php>. Acesso em: 24 ago. 2017. p. 25.

${ }^{24}$ ROCHA, Fernando Luiz Ximenes. A incorporação dos tratados e convenções internacionais de direitos humanos no direito brasileiro. Revista de informação legislativa. v. 33, n. 130, abr./jun. 1996, Brasília, p. 77-81. Disponível em: <http://www2.senado.leg.br/bdsf/item/id/176450>. Acesso em: 30 ago. 2017. p. 81

25 PIOVESAN, Flávia. A Constituição brasileira de 1988 e os tratados internacionais de proteção aos direitos humanos. Revista Jurídica da Faculdade de Direito Dom Bosco (EOS). v. 2, n. 1, ano II, 2014. Disponível em: <http://www.dombosco.sebsa.com.br/faculdade/revista_direito/3edicao.php>. Acesso em: 24 ago. 2017. p. 25.

${ }^{26}$ A menção ao modelo de estado brasileiro como um verdadeiro Estado Democrático e de Direito, encontra-se exposta já no artigo primeiro do texto constitucional ao dispor que "art. $1^{\circ} \mathrm{A}$ República Federativa do Brasil, formada pela união indissolúvel dos estados e municípios e do Distrito Federal, constitui-se em Estado Democrático e de Direito e tem como fundamentos: I- a soberania; II- a cidadania; III- a dignidade da pessoa humana; IV- os valores sociais do trabalho e da livre iniciativa; V- o Pluralismo Político. 
Administração Pública e, por via de consequência ao Poder Executivo ${ }^{27}$. Se assim o é, portanto, resta clara a necessidade de que se encontrem instrumentos aptos a dar efetividade a tal premissa, sendo necessária à dogmática jurídica o exercício intelectual para tanto.

Pode-se dizer, desse modo, que, a partir do contexto constitucional trazido pela Constituição Federal de 1988 e a partir da construção contemporânea de um direito internacional dos direitos humanos, uma das premissas mais básicas do modelo de Estado adotado pelo Brasil é o de, através do trabalho conjunto dos poderes da República, buscar a ideal concretização e efetivação dos direitos humanos e fundamentais.

Isso se dará, por sua vez, a partir da seguinte lógica: Ao legislativo impende analisar e criar políticas aptas a dar o ideal cumprimento constitucional da matéria, incorporando os tratados internacionais; ao Executivo cumpre o papel de encontrar mecanismos que garantam a sua real efetividade, também criando e executando políticas públicas para tanto; ao Judiciário, por sua vez, resta o papel de guardião dos preceitos legais incorporados ao texto constitucional e aventados também no direito internacional, garantindo a sua proteção e concretização quando de eventual omissão ou violação dos outros poderes.

De todo modo, considerando as intenções do presente trabalho, deve-se dar uma verdadeira atenção em como se efetiva o cumprimento de tais intenções pela via administrativa, ou seja, como, no Brasil, os direitos humanos e fundamentais são protegidos e efetivados de maneira ideal. Cumpre tornar perceptível, ademais, se o são, de fato, efetivados da forma ideal e trazer à mesa uma proposta de instrumento que seja apto a garantir uma maior otimização de tais pressupostos, garantindo efetivamente o seu cumprimento pela via administrativa, com o devido respeito às intenções constitucionais de 1988.

Para isso, todavia, deve-se levar em conta, antes, como este controle e proteção dos direitos humanos vem sendo tratado no Brasil, notadamente a partir da ideia de controle de convencionalidade. Isto é, impende analisar o que vem a ser este controle de convencionalidade inerente às questões de direitos humanos e como ele vem sendo incorporado no Brasil, para que se possa, então, analisar se estas premissas notadamente utilizadas pelo Poder Judiciário, conforme se verá a seguir, podem também ter seu uso incorporado pela Administração Pública.

\section{A GARANTIA DOS DIREITOS HUMANOS EXERCIDO PELOS TRIBUNAIS}

Levando em conta as considerações acima tecidas, parece ser importante que se entenda, enfim, o que vem a ser entendido por controle de convencionalidade e como ele é realizado no Brasil. A noção de um controle efetivo em matéria de direitos humanos tem seu espaço no tempo, também, a partir da construção histórica já discorrida no primeiro item deste texto. Em verdade, a partir do período pós-segunda guerra, as formas de se pensar o Direito também passam por mudanças de perspectiva, passa-se a pensar o Direito para além das regras escritas e dos objetos postos - teoria

${ }^{27}$ Para aprofundamento no tema, em especial na consagração dos direitos fundamentais sociais, ver: CLĖVE, Clemerson, Mèrlin. Para uma dogmática constitucional emancipatória. Belo Horizonte: Fórum, 2012. Cap. 1. 
positivista -, entendendo-se que, além destas regras codificadas, o mundo jurídico também é composto por princípios que possuem também o caráter de norma jurídica ${ }^{28}$.

Nesse cenário, então, o Poder Judiciário, que antes tinha o papel de mero aplicador da lei, passa a ter um importante lugar em que lhe cabe, para além da aplicação, a interpretação das normas jurídicas.

Como bem relata Estefânia Barboza Queiroz, após o marco da metade do século XX, se tem uma mudança nos papéis do Estado, em especial nos países de tradição romano-germânicas (civil law) que tinham o centro de sua autoridade no Parlamento. Isso se justifica ante o surgimento do Judicial Review29, ou seja, a partir da possibilidade de limitação das maiorias no Parlamento através do Poder Judiciário30.

Assim, "o Judiciário, assume, deste modo, papel importante na proteção, realização e especialmente na interpretação dos direitos humanos e fundamentais nessa nova era, fenômeno este que se dá o nome de Revolução de Direitos Humanos"31.

Pode-se dizer, que neste novo cenário de "Revolução dos Direitos Humanos" e da nova perspectiva dada às Constituições, em que se interpretam, para além das regras, os princípios, todo o Direito, todas as leis, deve ser interpretado não somente através do filtro do texto constitucional ${ }^{32}$, mas também a partir do filtro do Direito Internacional em Matéria de Direitos Humanos. Conforme aduz Estefânia Queiroz Barboza, "os direitos humanos funcionam como parâmetro comum de controle de constitucionalidade tanto em países de common law quanto em países de tradição civil law"33.

Isto é, os Tribunais ganham um importante papel nesse novo panorama, especialmente no que se refere ao Judicial Review que é tomado como instrumento para a proteção dos direitos humanos. No Brasil, uma das vias pelas quais esse controle é feito se refere a utilização do chamado controle de convencionalidade, ou seja, na busca pela proteção dos direitos humanos "se tem como

28 Sobre o tema, ver, dentre outros: SANCHÍS, Luis Prieto. Constitucionalismo e positivismo. Cidade do México: Distribuiciones Fontamara, 2. ed., 1999; FIGUEROA, Alfonso Garcia. Constitucionalismo y positivismo. Revista espanõla de derecho constitucional, ano 18, num. 54, set-dez. 1998; CLÈVE, Clèmerson Merlin. O direito e os direitos: elementos para uma crítica do direito contemporâneo. 3. ed. Belo Horizonte: Fórum. 2011; SCHIER, Adriana da Costa Ricardo; FLORES, Pedro Henrique Brunken. Estado de direito, superação do positivismo e os novos rumos do constitucionalismo. Revista brasileira de teoria e constituição. Curitiba. v. 2, n. 2, p. 1208-1229, jul/dez. 2016.

${ }^{29}$ O Judicial Review pode ser entendido como controle de constitucionalidade das leis.

30 QUEIROZ, Estefânia Barboza. A revolução dos direitos humanos e a expansão do Judicial Review nos estados contemporâneos. Revista Direitos Fundamentais e Democracia, Curitiba, v. 13, n. 13, p. 42-63, jan./jun. 2013. P. 43.

${ }_{31}$ QUEIROZ, Estefânia Barboza. A revolução dos direitos humanos e a expansão do Judicial Review nos estados contemporâneos. Revista Direitos Fundamentais e Democracia, Curitiba, v. 13, n. 13, p. 42-63, jan./jun. 2013. p. 43.

${ }^{32}$ Sobre a ideia de Constituição como um filtro para a interpretação e aplicação das leis, ver: SCHIER, Paulo Ricardo. Filtragem constitucional: construindo uma nova dogmática jurídica. Sérgio Antonio Fabris Editor: Porto Alegre. 1999.

${ }^{33}$ QUEIROZ, Estefânia Barboza. A revolução dos direitos humanos e a expansão do Judicial Review nos estados contemporâneos. Revista Direitos Fundamentais e Democracia, Curitiba, v. 13, n. 13, p. 42-63, jan./jun. 2013. p. 45. 
parâmetro, para além da Constituição Brasileira, uma Convenção Internacional que o país tenha aceito no ordenamento jurídico doméstico e que verse sobre direitos humanos"34.

Segundo Valério de Oliveira Mazzuoli, a partir de uma teoria geral, o controle de convencionalidade no Brasil será aplicado sempre que houver afronta a um tratado de direitos humanos por uma norma doméstica menos benéfica ${ }^{35}$. Segundo o mesmo autor:

À medida que os tratados de direitos humanos ou são materialmente constitucionais (art. 5은 $\S 2^{\circ}, \mathrm{CF}$ ), ou material e formalmente constitucionais (art. 5은 $\$ 3^{\circ}, \mathrm{CF}$ ), é lícito entender que, para além do clássico controle constitucionalidade, deve ainda existir (doravante) um controle de convencionalidade das leis, que é a compatibilização da produção normativa doméstica com os tratados de direitos humanos ratificados pelo governo em vigor no país ${ }^{36}$.

No Brasil, um exemplo emblemático de controle de convencionalidade operado pelo Supremo Tribunal Federal se refere ao Recurso Extraordinário 466.343, no qual fora discutida a possibilidade, ou não, ante o disposto no Pacto de San José da Costa Rica, da prisão civil do depositário infiel ${ }^{37}$. Referida decisão é importante para o cenário nacional, vez que foi a partir deste momento que "o Brasil ingressou, jurisprudencial e definitivamente, na 'terceira onda' evolutiva do Estado, do Direito e da Justiça, que é a onda do internacionalismo (ou da internacionalização dos direitos humanos)"38. Mais ainda, referida decisão é marco importante, pois "reconheceu o valor supralegal, ou constitucional (se atendidos os requisitos da Emenda Constitucional, na forma do art. 60, §2º , com votação em cada Casa do Congresso Nacional, em dois turnos, aprovada se obtiver, em ambos, três quintos dos votos dos membros), dos Tratados Internacionais que versem sobre Direitos Humanos" 39 .

${ }^{34}$ GOMES, Eduardo Biacchi; GONÇALVES, Ane Elise Brandalise. O controle de convencionalidade, a convenção americana de direitos humanos e o crime de desacato. Revista Jurídica da Presidência. v. 18, n. 114, fev/maio, Brasília. 2016. p. 73-96. Disponível em: <https://revistajuridica.presidencia.gov.br/index.php/saj/article/view/1207>. Acesso em: 27 ago. 2017. p. 76.

35 MAZZUOLI, Valério de Oliveira. Teoria Geral do Controle de convencionalidade no Direito brasileiro. In: MARINONI, Luiz Guilherme; MAZZUOLI, Valério de Oliveira (Coord.). Controle de convencionalidade: Um panorama latino-americano: Brasil, Argentina, Chile, México Peru, Uruguai. 1. ed. Gazeta Jurídica: Brasília. 2013. p. 4.

36 MAZZUOLI, Valério de Oliveira. Teoria Geral do Controle de convencionalidade no Direito brasileiro. In: MARINONI, Luiz Guilherme; MAZZUOLI, Valério de Oliveira (Coord.). Controle de convencionalidade: Um panorama latino-americano: Brasil, Argentina, Chile, México Peru, Uruguai. 1. ed. Gazeta Jurídica: Brasília. 2013. p. 5.

37 MARINONI, Luiz Guilherme. Controle de convencionalidade (na perspectiva do direito brasileiro). In: MARINONI, Luiz Guilherme; MAZZUOLI, Valério de Oliveira (Coord.). Controle de convencionalidade: Um panorama latino-americano: Brasil, Argentina, Chile, México Peru, Uruguai. 1. ed. Gazeta Jurídica: Brasília. 2013. p. 59.

38 GOMES, Luiz Flávio; MAZZUOLI, Valério de Oliveira. Direito supraconstitucional: do absolutismo ao estado constitucional e humanista de direito. Coleção direito e ciências criminais, V. 5. São Paulo: Editora Revista dos Tribunais, 2010. p. 162.

39 GOMES, Eduardo Biacchi; GONÇALVES, Ane Elise Brandalise. O controle de convencionalidade, a convenção americana de direitos humanos e o crime de desacato. Revista Jurídica da Presidência. v. 18, n. 114, fev/maio, Brasília. 2016. p. 73-96. Disponível em: $<$ https://revistajuridica.presidencia.gov.br/index.php/saj/article/view/1207>. Acesso em: 27 ago. 2017. p. 78. 
A Emenda Constitucional acima mencionada, refere-se a de número 45/2004, que acrescentou o já mencionado $3^{\circ}{ }^{\circ}$, ao artigo $5^{\circ}$ da Constituição Federal de 1988, trazendo a possibilidade "dos tratados de direitos humanos serem aprovados com quórum qualificado, a fim de passarem (desde que ratificados e em vigor no plano internacional) de um status materialmente constitucional para a condição (formal) de tratados 'equivalentes às emendas constitucionais"” 40.

A partir dessa decisão emblemática, portanto, se torna mais nítida a importância da incorporação e respeito dos tratados internacionais pelo Brasil. Isto é, o Direito pátrio deve levar em conta, seja no momento de uma decisão judicial, seja no momento de uma decisão administrativa ou, até mesmo, na execução de uma política pública, não mais somente o posto no texto constitucional e os princípios ali insculpidos, mas, para além disso, o disposto nos documentos e convenções internacionais de proteção dos direitos humanos.

Vale ressaltar, ademais, que, em não havendo o devido respeito aos dispositivos internacionais em matéria de direitos humanos, bem como 0 ineficiente controle de convencionalidade pelos Tribunais Pátrios, o caso concreto em apreço pode ser objeto de análise, no caso do Brasil, pela Comissão Interamericana de Direitos Humanos e pela Corte Interamericana de Direitos Humanos, levando, inclusive, à possibilidade de responsabilização internacional do Estado ${ }^{4142}$.

O importante a se extrair do relatado é que, como faz exemplo a decisão judicial no caso da prisão civil do depositário infiel, o Brasil, através do controle de convencionalidade exercido, ou seja, através do respeito ao conteúdo dos tratados e convenções internacionais de direitos humanos, se antecipa e decide questões importantes referentes a proteção dos direitos da humanidade sem a necessidade de que os casos sejam analisados pela corte, garantindo uma maior proteção e realização de tais direitos, ao mesmo tempo que evita eventuais sanções internacionais.

Se este é o caso, portanto, cumpre-se analisar, no próximo item, a proposta do trabalho propriamente dita, isto é: vislumbrar a possibilidade de que antes mesmo do exercício de um controle de convencionalidade pelo Poder Judiciário, a Administração Pública se utilize de tal desiderato no

40 MAZZUOLI, Valério de Oliveira. Teoria Geral do Controle de convencionalidade no Direito brasileiro. In: MARINONI, Luiz Guilherme; MAZZUOLI, Valério de Oliveira (Coord.). Controle de convencionalidade: Um panorama latino-americano: Brasil, Argentina, Chile, México Peru, Uruguai. 1. ed. Gazeta Jurídica: Brasília. 2013. p. 5.

${ }^{41}$ GOMES, Eduardo Biacchi; GONÇALVES, Ane Elise Brandalise. O controle de convencionalidade, a convenção americana de direitos humanos e o crime de desacato. Revista Jurídica da Presidência. v. 18, n. 114, fev/maio, Brasília. 2016. p. 73-96. Disponível em: $<$ https://revistajuridica.presidencia.gov.br/index.php/saj/article/view/1207>. Acesso em: 27 ago. 2017. p. 79.

42 Nesse mesmo sentido, ressaltam Eduardo Biacchi Gomes e Ane Elise Brandalise Gonçalves que, no que se refere ao controle de convencionalidade, este encontra respaldo no " próprio sistema interamericano dos direitos humanos, uma vez que já decidiu a própria Corte que a observância dos direitos conferidos em Tratados Internacionais que versem sobre direitos humanos e sua compatibilidade com as normas do direito interno constituem dever do Poder Judiciário, sendo que a negativa em assim proceder leva à responsabilidade internacional do Estado". (GOMES, Eduardo Biacchi; GONÇALVES, Ane Elise Brandalise. O controle de convencionalidade, a convenção americana de direitos humanos e o crime de desacato. Revista Jurídica da Presidência. v. 18, n. 114, fev/maio, Brasília. 2016. p. 73-96. Disponível em: $<$ https://revistajuridica.presidencia.gov.br/index.php/saj/article/view/1207>. Acesso em: 27 ago. 2017. p. 79). 
seu próprio âmbito decisório administrativo, formulando políticas públicas para além do disposto somente nas leis, mas também do disposto no direito internacional da humanidade.

\section{DIREITOS HUMANOS E ADMINISTRAÇÃO PÚBLICA: A incorporação dos tratados e convenções de direitos humanos na formulação de políticas públicas}

Pois bem. Do visto até aqui, pôde-se perceber a importância dos direitos humanos para a contemporaneidade, de forma a influenciar as relações existentes no mundo, sejam as relações estatais, sejam as relações sociais. No Brasil, como já afirmado, a matéria referente aos direitos humanos começou a ser tratada de forma ímpar e elevada à categoria de normas constitucionais, a partir do momento de redemocratização do país e, mais especificamente, após a promulgação da Constituição Federal de $1988^{43}$.

Nesse sentido, então, a Carta Constitucional mostra uma preocupação imanente com a manutenção e proteção dos direitos humanos, insculpindo em seu texto de forma expressa, inclusive, os direitos fundamentais (não excluindo demais direitos que possam ser, através da interpretação, incluídos nessa seara), os quais decorrem dos próprios ideais intimamente ligados à "revolução dos direitos humanos" e à proteção e concretização do princípio da dignidade da pessoa humana.

Nesse panorama, dentre toda a gama de direitos fundamentais existentes, uma de suas categorias de direitos possui uma peculiaridade e importância ímpar no que se refere à proteção e realização dos direitos humanos. Tal categoria se refere aos direitos fundamentais sociais, direitos que exigem, em regra, prestações positivas por parte do Estado para a sua ideal concretização ${ }^{44}$. Está-se a falar, aqui, a respeito de direitos como os de educação, saúde, moradia, cultura, alimentação, segurança, auxílio aos desamparados e etc., ou seja, direitos cuja real efetivação garante o verdadeiro exercício da democracia e da própria cidadania ${ }^{45}$.

Tal afirmação se justifica, vez que "a ausência ou a insuficiência dos direitos sociais, como trabalho (renda), educação, saúde, moradia, alimentação, bem como a existência de circunstâncias e

43 Conforme aponta Maria Paula Dallari Bucci, "Os direitos humanos expressam-se mais em princípios que em regras, isto é, eles em geral são valores que devem compor o espírito das demais normas. Os direitos humanos, cristalizados em princípios constitucionais (tais como os inscritos nos artigos $1^{\circ}$ e $5^{\circ}$ da Constituição Federal de 1988), servem de .critério para a exata compreensão e inteligência das demais normas. BUCCI, Maria Paula Dallari. Buscando um conceito de políticas públicas para a concretização dos direitos humanos. In: BUCCI, Maria Paula Dallari et alli. Direitos humanos e políticas públicas. São Paulo, Pólis, 2001.60p. p. 10.

${ }^{44}$ Não se excluí ou deixa de se considerar a importância dos outros direitos fundamentais existentes no texto constitucional ou que, através da interpretação, venham a ser elencados nessa categoria. Faz-se referida afirmação, todavia, vez que se entende que sem uma ideal realização dos direitos fundamentais sociais, até mesmo os demais direitos - tidos como direitos de liberdade, notadamente insculpidos no artigo $5^{\circ}$ da Constituição Federal de 1988 - tem sua plena realização prejudicada, faltando-lhes eficácia.

45 Sobre tal afirmação, ver, dentre tantos outros: TORRES, Ricardo Lobo. O direito ao mínimo existencial. Rio de Janeiro: Renovar. 2009. 
arranjos sociais que dificultam o acesso a esses direitos e à vida digna, criam sérios obstáculos ao exercício de todos os outros direitos humanos e fundamentais, das liberdades" ${ }^{46}$.

Fica patente, deste modo, a necessidade de que o Estado tome medidas concretas e aptas a assegurar a ideal concretização destes direitos - dentro de suas possibilidades fáticas e jurídicas -, a fim de cumprir com seu papel constitucional e, ainda mais, com a plena realização dos direitos humanos, estejam eles elencados explicitamente na Constituição ou não.

Se assim o é, portanto, mostra-se de extrema importância "a adoção de medidas concretas, planejadas e bem definidas para a realização desses direitos", de tal sorte que, inegavelmente, se percebe uma relação simbiótica entre a realização destes direitos e a existência de políticas públicas que tenham por si esse enfoque ${ }^{47}$.

Pois, é por meio delas - políticas públicas -, ao fixarem diretrizes para o Poder Público -, que os direitos sociais são efetivamente realizados ${ }^{48}$, vez que a sua atuação se dá de forma a complementar o já estatuído no texto constitucional e nos tratados e convenções de direitos humanos, ou seja, como bem aponta Maria Paula Dallari Bucci, "[...] as políticas públicas atuam de forma complementar, preenchendo os espaços normativos e concretizando os princípios e regras, com vista a objetivos determinados. As políticas, diferentemente das leis, não são gerais e abstratas, mas, ao contrário, são forjadas para a realização de objetivos determinados" 49 .

Perceba-se, assim, que as políticas públicas são ações governamentais, notadamente tomadas pela Administração Pública, para a realização, em especial, dos direitos fundamentais e fundamentais sociais. Sendo assim, deve-se perceber, também, uma mudança de perspectiva e uma provocação em se pensar que a ideal proteção e realização dos direitos humanos deve se dar, primeiramente, pela própria via administrativa. No que se refere ao presente trabalho, portanto, sobre a real possibilidade de que a Administração Pública tome decisões administrativas, criando e executando políticas públicas, levando em consideração e se vinculando aos tratados e convenções de direitos humanos, isto é, ao direito internacional dos direitos humanos. Ou seja: Sobre a possibilidade de que a própria Administração Pública realize o seu controle de convencionalidade administrativo ${ }^{50}$.

46 ARZABE, Patrícia Helena Massa. Conselhos de direitos e formulação de políticas públicas. In: BUCCI, Maria Paula Dallari et alli. Direitos humanos e políticas públicas. São Paulo, Pólis, 2001. 60p. p. 32.

47 ARZABE, Patrícia Helena Massa. Conselhos de direitos e formulação de políticas públicas. In: $\mathrm{BUCCl}$, Maria Paula Dallari et alli. Direitos humanos e políticas públicas. São Paulo, Pólis, 2001. 60p. p. 32.

48 ARZABE, Patrícia Helena Massa. Conselhos de direitos e formulação de políticas públicas. In: BUCCI, Maria Paula Dallari et alli. Direitos humanos e políticas públicas. São Paulo, Pólis, 2001. 60p. p. 32.

${ }^{49}$ BUCCI, Maria Paula Dallari. Buscando um conceito de políticas públicas para a concretização dos direitos humanos. In: BUCCI, Maria Paula Dallari et alli. Direitos humanos e políticas públicas. São Paulo, Pólis, 2001. 60p. p. 11.

${ }^{50}$ Entende-se como 'controle de convencionalidade administrativo', de acordo com os fins propostos no presente trabalho, a incorporação dos dispositivos internacionais de proteção dos direitos humanos, nas decisões administrativas, independentemente de sua positivação no ordenamento jurídico pátrio. Ou seja, é o dever de que a Administração Pública leve em consideração, no momento de decidir sobre determinado caso concreto, os preceitos internacionais constantes nos tratados e convenções sobre direitos humanos. 
A justificativa para tal proposta encontra seu mote do fato de que, se os direitos humanos devem ser elevados à categoria de normas constitucionais, tendo, consequentemente, aplicabilidade plena, estando conectados e vinculados com a dignidade da pessoa humana, buscar meios de garantir o maior grau de sua realização é fundamento básico de Estados que se auto intitulam como Estados de Direito e que possuem como fundamento basilar a proteção da dignidade da pessoa humana, como é o caso do Brasil ${ }^{51}$.

Diante disso, não se deve/pode pensar que o único mecanismo adequado para garantir a realização dos direitos humanos ou o seu controle em caso de violações seja através do controle de convencionalidade operado pelo Poder Judiciário. Isso porque, a perspectiva dada aos direitos humanos e demonstrada neste texto, exige mais do que isso. Exige que a Administração Pública, antes da necessidade de qualquer respaldo judicial, leve em consideração e aplique os preceitos e normas de direito internacional humano quando de suas decisões administrativas, de modo a fomentar políticas públicas aptas a dar concretude a tais fins.

Deve-se ter em conta que o princípio da legalidade, inerente às relações estatais, parte da interpretação não mais só da lei escrita, mas, também, dos princípios constitucionais, de tal sorte que os fundamentos das decisões administrativas podem ser encontrados, também, diretamente no próprio texto constitucional, bem como podem "legitimar-se perante o direito, ainda que contra lei, porém com fulcro numa ponderação da legalidade com outros princípios constitucionais (atividade contra legem, mas com fundamento numa otimizada aplicação da Constituição)"52.

Veja-se, portanto, que a Administração Pública não pode, sob um pseudo pretexto legalista, deixar de levar em conta os direitos humanos mesmo que não expostos explicitamente nas leis ou nos textos constitucionais. Sua interpretação, no momento de tomar determinada decisão administrativa nessa matéria, deve levar em conta todos os dispositivos legais - sejam eles nacionais ou internacionais - que busquem garantir da melhor forma possível a realização dos direitos humanos e, também, dos direitos fundamentais.

Tal afirmação encontra respaldo nos preceitos insculpidos na Convenção de Viena sobre o Direito dos Tratados, ratificada pelo Brasil, ao aduzir em seus artigos 26 que "todo tratado em vigor obriga as partes e deve ser cumprido por elas de boa fé" e 27 ao afirmar que "uma parte não pode invocar as disposições de seu direito interno para justificar o inadimplemento de um tratado".

O pacto de San José da Costa Rica, ao determinar, em seu artigo $1^{\circ}$ que "os Estados Partes nesta Convenção comprometem-se a respeitar os direitos e liberdades nela reconhecidos e a garantir seu livre e pleno exercício a toda pessoa que esteja sujeita à sua jurisdição, sem discriminação alguma por motivo de raça, cor, sexo, idioma, religião, opiniões políticas ou de qualquer outra natureza, origem nacional ou social, posição econômica, nascimento ou qualquer outra condição social" e, sequencialmente no seu artigo $2^{\circ}$, ao aduzir que "se o exercício dos direitos e liberdades mencionados no artigo 1 ainda não estiver garantido por disposições legislativas ou de outra natureza, os Estados Partes comprometem-se a adotar, de acordo com as suas normas constitucionais e com as disposições

51 Lembre-se que o texto constitucional de 1988 elenca como fundamento da República Federativa o princípio da dignidade da pessoa humano em seu artigo $1^{\circ}$, inciso III.

52 BINEMBOJM, Gustavo. Uma teoria do direito administrativo: direitos fundamentais, democracia e constitucionalização. 2. ed. rev. atual. Rio de Janeiro: Renovar. 2008. p. 516. 
desta Convenção, as medidas legislativas ou de outra natureza que forem necessárias para tornar efetivos tais direitos e liberdades". Veja-se, assim, que as próprias convenções ratificadas pelo Brasil impõem e dão o embasamento necessário para a proposta neste trabalho defendida.

Obviamente, todavia, que tais decisões devem levar em conta as peculiaridades fáticas e jurídicas do caso concreto, buscando garantir a decisão mais racional e efetiva.

De tal modo que, a partir deste momento, ela estará não somente construindo uma linha de decisões intimamente relacionadas com os fins constitucionais e em respeito ao princípio da dignidade da pessoa humana, como também estará em acordo com os verdadeiros ideais de um modelo de Estado Democrático e de Direito53.

\section{CONSIDERAÇÕES FINAIS}

Os direitos humanos, por certo, devem ser considerados como pedras angulares para a vida do homem na contemporaneidade. A partir da concepção tida, especialmente após a metade do século $\mathrm{XX}$, em que se alçou o princípio da dignidade da pessoa humana como fundamento a ser protegido através de uma união entre Estados e sociedades, a sua importância de mostrou ainda mais evidente.

Nesse cenário, ao Direito recaiu um importante papel de encontrar meios aptos a garantir a sua real e efetiva proteção e realização, seja através da formulação de tratados internacionais com força vinculativa para com os Estados signatários, seja através da própria criação de instrumentos domésticos que visassem propiciar da melhor formar os fins necessários e almejados. Por certo, se está diante de um cenário revolucionário dos direitos humanos, em constante evolução.

\footnotetext{
${ }^{53}$ Aqui, pode-se extrair, inclusive, a ideia de que ao tomar tais decisões, a Administração Pública se autovincula as mesmas, devendo respeita-las sempre que se deparar com casos similares que possuam o mesmo suporte fático da decisão anterior. Em outras palavras: Tais decisões podem e devem se tornar precedentes administrativos a serem respeitados pela Administração Pública com o fim primeiro de garantir a maior otimização das prestações estatais, protegendo e realizando os direitos humanos e fundamentais e, ainda mais, respeitando aos princípios administrativos e constitucionais a si imanentes, especialmente os princípios da isonomia e segurança jurídica. Tal ideia - de vinculação da Administração Pública às suas próprias decisões, formando precedentes administrativos, ainda é recente no Brasil, tendo, todavia, um maior campo de estudo na doutrina estrangeira. Sobre o tema no Brasil, ver: HACHEM, Daniel Wunder. Vinculação da Administração Pública aos precedentes administrativos e judiciais: mecanismo de tutela igualitária dos direitos sociais. In: BLANCHET, Luiz Alberto; HACHEM, Daniel Wunder; SANTANO, Ana Cláudia. (coord.). Estado, direito e políticas públicas: Homenagem ao professor Romeu Felipe Bacellar Filho. Curitiba: Íthala, 2014; CARVALHO, Gustavo de Marinho. Precedentes administrativos no direito brasileiro. São Paulo: Editora Contracorrente, 2015; WACHELESKI, Marcelo Paulo; FLORES, Pedro Henrique Brunken. Precedentes administrativos, efetividade dos direitos fundamentais e a proposta de releitura do princípio da supremacia do interesse público. Juris plenum: direito administrativo, v. 3, n. 10, p. 167-182, jun., 2016. Ainda, sobre o tema na doutrina estrangeira, ver, dentre outros: DIAZ, José Ortiz. El precedente administrativo. Revista de Administración Pública. Espanha. n. 24. p. 75116. 1957. Disponível em: <http://dialnet.unirioja.es/servlet/articulo?codigo=2112205>; GAMBOA, Jaime Orlando Santofimio. La fuerza de los precedentes administrativos en el sistema jurídico del derecho positivo colombiano. Revista de derecho de la Universidad de Montevideo. 2010. Disponível em: <http://revistaderecho.um.edu.uy/wp-content/uploads/2012/12/Santofimio-Gamboa-Lafuerza-de-los-precedentes-administrativos-en-el-sistema-juridico-del-derecho-positivocolombiano.pdf>; MARTíNEZ, Augusto Durán. El precedente administrativo. Revista de Derecho de La Universidad del Uruguay. 2010.
} 
Desse modo, procurou-se mostrar no presente texto que, ante a essa ótica, devem ser pensadas formas de se proteger e garantir os direitos humanos e fundamentais para além das já existentes, demonstrando-se a importância de que todos os órgãos de poder trabalhem em conjunto na busca pela proteção dos direitos humanos, notadamente, no entanto, a partir de uma ótica primária da própria Administração Pública, que detêm, de acordo com a interpretação do texto constitucional de 1988, a competência primeira em proteger e efetivar os direitos fundamentais e humanos dos homens.

Diante disso, a intenção central foi a de justificar a necessidade e importância de que exista, para além de um controle judicial no que se refere à proteção dos direitos humanos, um meio de se efetivar e proteger tais direitos pela via administrativo, ou seja, através da formulação de decisões administrativas que estejam pautadas não somente na lei e no texto constitucional, mas também nos dispositivos constantes dos tratados e convenções de direito internacional humano.

A essa proposta, tomou-se a liberdade de dar-Ihe a nomenclatura de "controle de convencionalidade administrativo", justificando-a, por sua vez, devido ao fato de que se estariam protegendo e realizando os direitos humanos e fundamentais, especialmente os de cunho social, de forma equânime, segura e, buscando o melhor resultado lógico possível, sem a necessidade de um controle jurisdicional.

\section{REFERÊNCIAS}

ARZABE, Patrícia Helena Massa. Conselhos de direitos e formulação de políticas públicas. In: $\mathrm{BUCCl}$, Maria Paula Dallari et alli. Direitos humanos e políticas públicas. São Paulo, Pólis, 2001. 60p. p. 32.

BARROSO, Luís Roberto. Curso de direito constitucional contemporâneo: os conceitos fundamentais e a construção do novo modelo. 5. ed. São Paulo. Saraiva. 2014. VitalBook file. Disponível em: <http://integrada.minhabiblioteca.com.br/books/9788502228061 z. Acesso em: 27 set. 2016.

BINEMBOJM, Gustavo. Uma teoria do direito administrativo: direitos fundamentais, democracia e constitucionalização. 2. ed. rev. atual. Rio de Janeiro: Renovar. 2008.

BOBBIO, Norberto. A era dos direitos. Rio de Janeiro: Elsevier. 2004.

BUCCI, Maria Paula Dallari. Buscando um conceito de políticas públicas para a concretização dos direitos humanos. In: BUCCI, Maria Paula Dallari et alli. Direitos humanos e políticas públicas. São Paulo, Pólis, 2001. 60p.

BRUGGER, Winfried; LEAL, Monia. Os direitos fundamentais nas modernas constituições: análise comparativa entre as Constituições Alemã, Norte-americana e Brasileira. Revista do Direito, Santa Cruz do Sul, p. 123-142, jul. 2007. ISSN 1982-9957. Disponível em: $<$ https://online.unisc.br/seer/index.php/direito/article/view/184/143>. Acesso em: 21 jun. 2019. doi:https://doi.org/10.17058/rdunisc.v0i28.184.

CANÇADO TRINDADE, Antônio Augusto. Dilemas e desafios da proteção internacional dos direitos humanos no limiar do século XXI. Revista brasileira de Política Internacional. Vol. 40, n. 1, Brasília, jan/jun. $\quad 1997 . \quad$ Disponível em: <http://www.scielo.br/scielo.php?pid=S003473291997000100007\&script=sci_arttext\&tlng=pt>. Acesso em: 30 ago. 2017.

CARVALHO, Gustavo de Marinho. Precedentes administrativos no direito brasileiro. São Paulo: Editora Contracorrente, 2015; 
CLÈVE, Clèmerson Merlin. O direito e os direitos: elementos para uma crítica do direito contemporâneo. 3. ed. Belo Horizonte: Fórum. 2011;

CLĖVE, Clèmerson, Merlin. Para uma dogmática constitucional emancipatória. Belo Horizonte: Fórum, 2012.

COMPARATO, Fábio Konder. A afirmação histórica dos direitos humanos. 4. ed. rev. e atual. São Paulo: Saraiva, 2005.

FACHIN, Melina Giraldi. Fundamentos dos direitos humanos: teoria e práxis na cultura da tolerância. Rio de Janeiro: Renovar

FERRAÇO, André Augusto Giuriatto; MORAES, Gabriela Garcia Batista Lima. O controle de convencionalidade do crime de desacato e o sistema interamericano de direitos humanos na redemocratização na américa-latina: uma análise com base no caso brasileiro. Revista do Direito, Santa Cruz do Sul, v. 2, n. 55, p. 76-95, maio 2018. ISSN 1982-9957. Disponível em: <https://online.unisc.br/seer/index.php/direito/article/view/11875/7665>. Acesso em: 21 jun. 2019. doi:https://doi.org/10.17058/rdunisc.v2i55.11875.

FIGUEROA, Alfonso Garcia. Constitucionalismo y positivismo. Revista espanõla de derecho constitucional, ano 18, num. 54, set-dez. 1998;

GOMES, Eduardo Biacchi; GONÇALVES, Ane Elise Brandalise. O controle de convencionalidade, a convenção americana de direitos humanos e o crime de desacato. Revista Jurídica da Presidência. v. $18, \quad$ n. 114, fev/maio, Brasília. 2016. p. 73-96. Disponível em: <https://revistajuridica.presidencia.gov.br/index.php/saj/article/view/1207>. Acesso em: 27 ago. 2017.

GOMES, Luiz Flávio; MAZZUOLI, Valério de Oliveira. Direito supraconstitucional: do absolutismo ao estado constitucional e humanista de direito. Coleção direito e ciências criminais, V. 5. São Paulo: Editora Revista dos Tribunais, 2010. p. 162.

HACHEM, Daniel Wunder. Vinculação da Administração Pública aos precedentes administrativos e judiciais: mecanismo de tutela igualitária dos direitos sociais. In: BLANCHET, Luiz Alberto; HACHEM, Daniel Wunder; SANTANO, Ana Cláudia. (coord.). Estado, direito e políticas públicas: Homenagem ao professor Romeu Felipe Bacellar Filho. Curitiba: Íthala, 2014;

LAFER, Celso. A ONU e os direitos humanos. Estudos avançados. v. 9, n. 25, São Paulo, set/dec. 1995. Disponível em: <http://www.scielo.br/scielo.php?pid=S0103$40141995000300014 \&$ script=sci_arttext\&tlng=pt>. Acesso em: 27 ago. 2017.

LOPES, Ana Maria D’Ávila; TOMÉ, Semiramys Fernandes. A inaplicabilidade imediata do regime disciplinar diferenciado com base no controle de convencionalidade. Revista do Direito, Santa Cruz do Sul, v. 2, n. 52, p. 3-17, out. 2017. ISSN 1982-9957. Disponível em: <https://online.unisc.br/seer/index.php/direito/article/view/8486/6838>. Acesso em: 21 jun. 2019. doi:https://doi.org/10.17058/rdunisc.v2i52.8486.

MARINONI, Luiz Guilherme. Controle de convencionalidade (na perspectiva do direito brasileiro). In: MARINONI, Luiz Guilherme; MAZZUOLI, Valério de Oliveira (Coord.). Controle de convencionalidade: Um panorama latino-americano: Brasil, Argentina, Chile, México Peru, Uruguai. 1. ed. Gazeta Jurídica: Brasília. 2013.

MAZZUOLI, Valério de Oliveira. Teoria Geral do Controle de convencionalidade no Direito brasileiro. In: MARINONI, Luiz Guilherme; MAZZUOLI, Valério de Oliveira (Coord.). Controle de convencionalidade: Um panorama latino-americano: Brasil, Argentina, Chile, México Peru, Uruguai. 1. ed. Gazeta Jurídica: Brasília. 2013.

ORGANIZAÇÃO DAS NAÇÕES UNIDAS (ONU). Declaração universal dos direitos humanos. 1948. 
PIOVESAN, Flavia; DE FREITAS, Daniel Castanha. O pacto de San José da Costa Rica e a jurisprudência interamericana em matéria de direito à saúde. Revista do Direito, Santa Cruz do Sul, v. 1 , n. 54, p. 205-225, jan. 2018. ISSN 1982-9957. Disponível em: $<$ https://online.unisc.br/seer/index.php/direito/article/view/11843/7331>. Acesso em: 21 jun. 2019. doi:https://doi.org/10.17058/rdunisc.v1i54.11843.

PIOVESAN, Flávia. A Constituição brasileira de 1988 e os tratados internacionais de proteção aos direitos humanos. Revista Jurídica da Faculdade de Direito Dom Bosco (EOS). v. 2, n. 1, ano II, 2014. Disponível em: <http://www.dombosco.sebsa.com.br/faculdade/revista_direito/3edicao.php>. Acesso em: 24 ago. 2017.

PIOVESAN, Flávia. A universalidade e a indivisibilidade dos direitos humanos: desafios e perspectivas. In: BALDI, César Augusto (Org.). Direitos humanos na sociedade cosmopolita. Rio de Janeiro: Renovar. 2004.

QUEIROZ, Estefânia Barboza. A revolução dos direitos humanos e a expansão do Judicial Review nos estados contemporâneos. Revista Direitos Fundamentais e Democracia, Curitiba, v. 13, n. 13, p. 42-63, jan./jun. 2013.

ROCHA, Fernando Luiz Ximenes. A incorporação dos tratados e convenções internacionais de direitos humanos no direito brasileiro. Revista de informação legislativa. v. 33, n. 130, abr./jun. 1996, Brasília, p. 77-81. Disponível em: <http://www2.senado.leg.br/bdsf/item/id/176450>. Acesso em: 30 ago. 2017.

SANCHÍS, Luis Prieto. Constitucionalismo e positivismo. Cidade do México: Distribuiciones Fontamara, 2. ed., 1999;

SCHIER, Adriana da Costa Ricardo; FLORES, Pedro Henrique Brunken. Estado de direito, superação do positivismo e os novos rumos do constitucionalismo. Revista brasileira de teoria e constituição. Curitiba. v. 2, n. 2, p. 1208-1229, jul/dez. 2016.

SCHIER, Paulo Ricardo. Filtragem constitucional: construindo uma nova dogmática jurídica. Sérgio Antonio Fabris Editor: Porto Alegre. 1999.

TORRES, Ricardo Lobo. O direito ao mínimo existencial. Rio de Janeiro: Renovar. 2009.

WACHELESKI, Marcelo Paulo; FLORES, Pedro Henrique Brunken. Precedentes administrativos, efetividade dos direitos fundamentais e a proposta de releitura do princípio da supremacia do interesse público. Juris plenum: direito administrativo, v. 3, n. 10, p. 167-182, jun., 2016.

\section{COMO CITAR ESSE DOCUMENTO:}

GOMES, Eduardo Biacchi; FLORES, Pedro Henrique Brunken. Formulação de decisões administrativas em matéria de direitos humanos. Revista do Direito, Santa Cruz do Sul, v. 1, n. 57, jul. 2019. ISSN 1982-9957. Disponível em: <https://online.unisc.br/seer/index.php/direito/article/view/11831>. Acesso em: . doi:https://doi.org/10.17058/rdunisc.v1i57.11831. 